\title{
Pancreatic Society of Great Britain and Ireland
}

The Annual Scientific Meeting of the Society was held on 24 November 1995 at the Hyatt Regency Hotel, Birmingham, under the presidency of Professor J P Neoptolemos. The Visiting Lecturer was Professor M Büchler from Berne. The winner of the Rodney Smith Medal and Prize was Dr N K Green from Birmingham. Mr S J Wigmore won the Poster Prize and two further travel prizes were awarded to Mr F Curran and Mr S Galloway.

\section{Outcome of surgery for chronic pan- creatitis}

J D EVANS, P G WILSON, S R BRAMHALL, J P NEOPTOLEMOS (Department of Surgery $\mathcal{E}$ Medicine, Queen Elizabeth Hospital, Birmingham) Forty five consecutive patients (38 men, seven women; median 42 years, range 23-72) who had surgery for chronic pancreatitis were studied prospectively over a seven year period. In $80 \%$ of patients chronic pancreatitis was due to alcohol. The diagnosis was confirmed by histology in all patients. In 43 patients the principal indication for surgery was pain. Nineteen patients had a duodenum preserving resection of the pancreatic head (Beger); the other surgical procedures were Whipple's resection (4), left sided resection (8), total pancreatectomy (6), pseudocyst-jejunostomy (4), and bypass procedures (4). The median inpatient stay was 13 days with no operative mortality but 12 patients had postoperative complications.

There was improved pain control $(p<0.0001)$, a trend towards weight increase (not statistically significant), and return to fistulogram (5) or at the time of surgery (4). In nine patients the fistula was complicated by infection (5), pancreaticopleural fistula (2), involvement of the bilary tract (1) or duodenum (1). Treatment was conservative in 12 patients, five of whom needed imaging guided drainage. One patient died of necrotising pancreatitis. All other fistulas closed. Surgical intervention was used in nine patients: internal drainage (6), resection (2), and oversewing of internal fistula combined with pancreaticogastrostomy (1). All operations resulted in closure of the fistula with no deaths. No recurrences occurred during the follow up period of two to 74 months (mean 28 months). Successful closure of pancreatic fistulas can be achieved by conservative management in most cases arising after pancreatic necrosectomy or resectional surgery.

Operation is required for fistula arising after trauma, or persisting more than six weeks after necrosectomy or percutaneous drainage. Associated pseudocyst usually requires operative internal drainage. With appropriate management mortality is low.

\begin{tabular}{llllllll}
\hline & Pre-op & 6 Months & 1 Year & 2 Years & 3 Years & 4 Years & 5 Years \\
\hline No at risk & 45 & 35 & 30 & 19 & 15 & 10 & 7 \\
Weight $(\mathrm{kg})^{\star}$ & 60 & 62 & 66 & 67 & 69 & 63 & 71 \\
Pain (regular & $(38,96)$ & $(45,88)$ & $(45,93)$ & $(49,99)$ & $(50,98)$ & $(54,101)$ & $(58,103)$ \\
& 43 & 16 & 15 & 3 & 4 & 3 & 0 \\
Enzyme supplements & $(96 \%)$ & $(46 \%)$ & $(50 \%)$ & $(16 \%)$ & $(27 \%)$ & $(30 \%)$ & 8 \\
Diabetes mellitus & $(18 \%)$ & $(71 \%)$ & $(67 \%)$ & $(68 \%)$ & $(53 \%)$ & $(80 \%)$ & $(71 \%)$ \\
& 12 & 13 & 12 & 11 & 10 & 7 & 5 \\
Employed & $(27 \%)$ & $(37 \%)$ & $(40 \%)$ & $(58 \%)$ & $(67 \%)$ & $(70 \%)$ & $(71 \%)$ \\
& 12 & 14 & 11 & 9 & 8 & 6 & 4 \\
& $(27 \%)$ & $(40 \%)$ & $(37 \%)$ & $(47 \%)$ & $(53 \%)$ & $(60 \%)$ & $(57 \%)$ \\
\hline
\end{tabular}

${ }^{\star}$ Median, range.

employment $(p<0 \cdot 01)$. Although there was an increase in diabetes mellitus $(p<0.0001)$ and enzyme supplementation $(p<0.001)$ digestion was easily maintained. Surgery for chronic pancreatitis is an effective treatment in selected patients (statistics: Kruskal-Wallis and $\chi^{2}$ for trend).

\section{Management of pancreatic fistula}

C D JOHNSON, A PRASAD (University Surgical Unit, Southampton General Hospital, Southampton) Pancreatic duct disruption due to disease, injury by trauma or surgery may result in a fistula. From 1989 to 1994, 21 patients with pancreatic fistula were seen. In 20 patients an external fistula (high output ( $>200 \mathrm{ml} /$ day) in 11) followed emergency necrosectomy or drainage for acute pancreatitis (13), elective surgery for tumours (4) or trauma (3). Chronic alcoholic pancreatitis resulted in one internal fistula. The diagnosis was confirmed by high fluid amylase in 14 patients and/or imaging by computed tomography (12), endoscopic retrograde cholangiopancreaticography (3),

\section{Laparoscopic pancreatic surgery}

MICHAEL J MCMAHON (Leeds Institute for Minimally Invasive Therapy and Division of Surgery, The General Infirmary, Leeds) The criteria for an operation that is appropriately carried out laparoscopically include the following: (a) avoidance of a large incision; (b) relatively small specimen size; (c) avoidance of extensive anastomosis.

With these criteria in mind there are many pancreatic procedures that theoretically fall within the laparoscopic surgeon's ambit, particularly cyst drainage, bypass procedures, and left sided resections.

This presentation, which will be $75 \%$ video, details an experience of laparoscopic pancreatic surgery, which includes cyst gastrostomy, cyst duodenostomy, binary bypass, enucleation of insulinoma, and left sided pancreatectomy for islet tumour, cyst-adenoma and chronic pancreatitis. The results suggest that laparoscopic techniques may have a substantial part to play in the armamentarium of the pancreatic surgeon.
Progressive disruption of the pancreatic acinar cell polarised calcium signal during experimental pancreatitis

J B WARD, M MORRIS, M HASHMI, R SUTTON*, O H PETERSEN (Physiological Laboratory and * Department of Surgery, University of Liverpool) Disruption of normal apical exocytosis has been described in early experimental acute pancreatitis, but the mechanisms by which this occurs are unclear. Cytoplasmic free ionised calcium $\left[\mathrm{Ca}^{2+}\right]_{\mathrm{i}}$ is a key pancreatic intracellular messenger, a polarised increase in $\left[\mathrm{Ca}^{2+}\right]_{\mathrm{i}}$ being important in regulating exocytosis from the secretory pole of the acinar cell. This study therefore examined spatial aspects of $\left[\mathrm{Ca}^{2+}\right]_{i}$ signalling during early experimental pancreatitis.

Mice received hourly injections of caerulein $(50 \mu \mathrm{g} / \mathrm{kg})$ or saline (controls). Pancreatic tissue was harvested after injections $1,3,5$, and 7 , and acini isolated with collagenase. Cells were loaded with fura-2 and the pattern of increase of $\left[\mathrm{Ca}^{2+}\right]_{i}$ in response to stimulation with $500 \mathrm{nM}$ acetylcholine (ACh) assessed using video digital imaging microfluorimetry.

\begin{tabular}{lllll}
\hline $\begin{array}{l}\text { Point of harvest } \\
\text { (injection) }\end{array}$ & 1 & 3 & 5 & 7 \\
\hline $\begin{array}{l}\text { Number (\%) of cells } \\
\text { demonstrating normal } \\
\text { pattern of }\left[\mathrm{Ca}^{2+}\right]_{\mathrm{i}} \\
\text { increase }\end{array}$ & $16 / 17$ & $12 / 18$ & $6 / 13$ & $3 / 6$ \\
\hline
\end{tabular}

The proportion of experimental cells (see Table) maintaining a normal pattern of increase in $\left[\mathrm{Ca}^{2+}\right]_{i}$ with initiation in the secretory poles progressively diminished during the course of caerulein injections $\left(\chi_{\text {trend }}^{2}=7 \cdot 38\right.$, $p<0.01)$. A high proportion of control cells maintained a normal signal throughout.

This loss of the physiological $\left[\mathrm{Ca}^{2+}\right]_{\mathrm{i}}$ signal could account for the disruption of exocytosis that has been described in this model, but further work is required to assess the importance of abnormal $\left[\mathrm{Ca}^{2+}\right]_{\mathrm{i}}$ signalling in acute pancreatitis.

Amelioration of acute pancreatitis using a TNF-metalloproteinase inhibitor in the microvascular ischaemia model of acute pancreatitis

P G SKAIFE, N S KULKAMI ${ }^{\star}, M$ WOOD, A N KINGSNORTH (Departments of Surgery and Pathology ${ }^{\star}$, University of Liverpool and British Biotechnology Group) TNF is a potent proinflammatory cytokine that has been shown to be an important mediator in the development of both local and systemic sequelae associated with severe acute pancreatitis.

The effect of a TNF metalloproteinase inhibitor BB1102, known to be active at the post-translational step in TNF production, was studied in the microvascular ischaemic 
model of acute pancreatitis in male Wistar rats. Administration of BB1 $102(3 \mathrm{mg} / \mathrm{kg}$ ), given as a single intraperitoneal dose 30 minutes after induction of acute pancreatitis, significantly reduced $(p=0.01)$ the rise of serum amylase (mean 2083; range 16462843 ) in treated animals $v$ controls (mean 2623; range 2071-3058), the pancreatic weight $(\mathrm{p}=<0.005)$, (mean $1.16 \mathrm{~g}$; range $0.84-1.4 \mathrm{~g}$ ) $v$ controls (mean $1.75 \mathrm{~g}$ range $0 \cdot 96-2.23 \mathrm{~g}$ ), and the histology score was also significantly reduced $(p=<0.001)$, (mean $8 \cdot 25$ range 5-11) $v$ control pancreata (mean 17; range 14-20).

Pancreatic tissue levels of TNF are increased in experimental acute pancreatitis. Treatment with a TNF metalloproteinase inhibitor effectively blocks TNF processing and so ameliorates the disease progression, which may represent a new therapeutic strategy.

The study of bacterial contamination of the peritoneum and pancreas in acute pancreatitis

P G SKAIFE, G SMITH, A N KINGSNORTH (Departments of Surgery and Microbiology, University of Liverpool) The major determinant in the outcome of acute necrotising pancreatitis in terms of morbidity and mortality is bacterial infection. Bacterial translocation from gut flora has been implicated in the pathogenesis of bacterial infection of the pancreas. The microvascular ischaemic model of acute pancreatitis provides a reproducible model of sepsis, not only of the pancreas, but also the peritoneum to further validate the translocation hypothesis.

Male Wistar rats (400-500 g) had pancreatitis induced, and two time points of 48 and 96 hours were taken to kill the animals.

Histological scoring revealed necrotising pancreatitis in all microsphere treated animals, while sham treated animal histology suggested no inflammation. Semi-quantitative microbiological analysis revealed gross peritoneal soiling along with pancreatic sepsis to correlate with the microsphere treated group in $100 \%$ of animals, with no significant difference between the $48 \mathrm{~h}(\mathrm{n}=12)$ and $96 \mathrm{~h}$ $(n=14)$ groups. Qualitatively, enterobacteria were isolated in both the peritoneum and pancreas in the acute pancreatitis group, while the controls had no growth or scanty skin commensals.

This model provides a reproducible model of acute necrotising pancreatitis resulting in peritonitis and pancreatic sepsis with a low mortality $(n=1)$, making it an ideal model for the fuller study of prophylaxis and treatment.

Controlled trial of lexipafant in severe acute pancreatitis

F J M CURRAN, C E SHARPLES, C A YOUNG, L CURTIS ${ }^{\star}$, C J MCKAY, J N BAXTER, C W IMRIE (University Departments of Surgery, Glasgow Royal Infirmary, ${ }^{\star}$ British Biotech Pharmaceuticals Ltd, Cowley, Oxford) A randomised, double blind placebo controlled trial examined the effect of a novel potent platelet activating factor (PAF) receptor antagonist, lexipafant (BB-882, British Biotech) in severe acute pancreatitis. Inclusion criteria were: (a) within 72 hours of the onset of pain; (b) serum amylase $>4 \times$ the upper limit of normal, and (c) either: (1) APACHE II score $>5$ or $(2) \geqslant 3$ positive Glasgow prognostic criteria or (3) C-reactive protein $>120 \mathrm{mg} /$.
Endoscopic retrograde cholangiopancreatography (ERCP) induced pancreatitis was excluded from the trial. Between April 1994 and May 1995, 188 patients with acute pancreatitis admitted to 11 hospitals in the west of Scotland were screened. A total of 51 patients were recruited: lexipafant $(n=27)$ and placebo $(n=24)$. The mean age, sex distribution, and aetiology distribution were similar for both groups. Patients received a continuous intravenous infusion of $100 \mathrm{mg}$ of lexipafant/day for 120 hours (APACHE 6-8), for 168 hours (APACHE $>8$ ) or until intravenous hydration was discontinued. Patients were clinically assessed daily for eight days. Organ failure scores were calculated daily for each patient using haemodynamic, biochemical, and haematological measures. The results are summarised in the Table.

\begin{tabular}{|c|c|c|}
\hline & Lexipafant & Placebo \\
\hline $\begin{array}{l}\text { Organ failure on admission (no } \\
\text { of patients) }\end{array}$ & $13 / 27$ & $6 / 24$ \\
\hline Organ failure reversal by 7 days & $8 / 13$ & $2 / 6$ \\
\hline $\begin{array}{l}\text { New organ failure continuing at } \\
7 \text { days }\end{array}$ & 1 & 4 \\
\hline Mortality & $4 / 27$ & $6 / 24$ \\
\hline $\begin{array}{l}\text { Mean (SEM) change in organ } \\
\text { failure score }\end{array}$ & $-1(0 \cdot 2)^{\star}$ & $+0.3(0.3)$ \\
\hline (range) & -3 to +1 & -2 to 4 \\
\hline
\end{tabular}

${ }^{\star} \mathrm{p}=0.004$, Wilcoxon rank sum test, lexipafant versus placebo.

These results suggest that lexipafant may be of benefit in the treatment of severe acute pancreatitis.

Acute pancreatitis: 144 patients treated in a tertiary referral centre

PAUL LEEDER, IAIN MARTIN, MICHAEL MCMAHON (Academic Department of Surgery, The General Infirmary at Leeds) Between 1988 and June 1995144 patients with acute pancreatitis were treated by one consultant (MJM). Of these, 70 were admitted from our local population and 74 were tertiary referrals from other consultants. The mean age was 53 years (17-91) and 90 patients were male. The aetiology was thought to be ethanol in 44 patients, gall stones in 51 , idiopathic in 33 , and due to other causes in 16 patients.

The ASA grades of the 144 patients were, ASA 176, ASA II 33, ASA III 33, and ASA IV 2 patients. The mean APACHE II score on admission was $7 \cdot 3$ (range $0-35$ ).

Dynamic CT imaging was performed in 99 patients and formed the basis for all subsequent management. Thirty four patients just had one CT scan, 23 patients two scans, 11 patients three scans, and 31 patients more than three scans.

Of the 144 patients, 74 were managed conservatively without operative or radiological intervention, 33 had radiological intervention, and 33 required operation. Forty of the 144 cases required intensive care support and 79 needed intravenous nutrition. Twenty six of the 144 patients required open pancreatic debridement. Of these 26 patients 18 died but eight survived.

Overall 26 of the $144(18 \%)$ patients died from their pancreatitis. The best predictor of overall mortality was the APACHE II score on admission $(p<0.001)$. The mean length of stay of patients was 44 days (range 1 to 173) and for those requiring operative debridement was $\mathbf{5 2}$ days.

This very sick group of patients pose a formidable challenge and place great demand upon the therapeutic and support services of the hospital. For the patient with severe acute pancreatitis the full range of therapeutic and support services should be available with management based upon clinical and radiological features and progress.

\section{Interleukin 10 in early acute pancreatitis}

S W GALLOWAY, A N KINGSNORTH (Department of Surgery, Royal Liverpool University Hospital) Interleukin 10 (IL-10) has been implicated as an important regulator of the immune functions of inflammatory cells through its ability to block synthesis of pro-inflammatory cytokines by macrophages and $\mathrm{T}$ lymphocytes. The aim of this study was to determine the serum concentrations of IL-10 in patients with acute pancreatitis on admission and on subsequent days and compare them with other markers of disease severity. Twenty patients (10 severe as defined by Atlanta criteria) underwent analysis of serum samples using an enzyme immunoassay kit for IL-10 (Genzyme, West Malling, Kent).

\begin{tabular}{|c|c|c|c|}
\hline \multirow{2}{*}{$\begin{array}{l}\text { Parameter } \\
\text { on } \\
\text { admission }\end{array}$} & \multicolumn{2}{|c|}{$\begin{array}{l}\text { Acute pancreatitis } \\
\text { (med/IQR) }\end{array}$} & \multirow{2}{*}{$\begin{array}{l}\text { Mann- } \\
\text { Whitney } \\
\text { U test }\end{array}$} \\
\hline & $\begin{array}{l}\text { Severe } \\
(n=10)\end{array}$ & $\begin{array}{l}\text { Mild } \\
(n=10)\end{array}$ & \\
\hline $\begin{array}{c}\text { PMNE } \\
(\mu \mathrm{g} / \mathrm{l}) \\
\mathrm{IL}-6 \\
(\mathrm{pg} / \mathrm{ml}) \\
\mathrm{IL}-10 \\
(\mathrm{ng} / \mathrm{ml})\end{array}$ & $\begin{array}{l}152 \\
468-132 \\
115 \\
233-35 \\
4 \cdot 6 \\
6 \cdot 4-2 \cdot 4\end{array}$ & $\begin{array}{l}127 \\
155-101 \\
143 \\
288-46 \\
12 \cdot 9 \\
19 \cdot 6-7 \cdot 1\end{array}$ & $\begin{array}{l}p=0.07 \\
p=0.7 \\
p<0.01\end{array}$ \\
\hline
\end{tabular}

Peak IL-10 values were seen in the mild group of pancreatitis on the first day of admission and decreased gradually thereafter. Values recorded in the severe group were similar to those seen in healthy human volunteers. These relatively low values in the severe form of the disease support the concept of an uncontrolled inflammatory response in the severe form of acute pancreatitis.

Serum carbohydrate deficient transferrin as a marker of alcohol intake in acute abdominal inflammatory conditions including acute pancreatitis

S K C TOH, D SLADE, V HAYLEY, C D JOHNSON (University Surgical Unit, Southampton General Hospital) Carbohydrate deficient transferrin (CDT) has been shown to be a reliable marker for alcohol abuse in patients with chronic liver disease and recently, in acute pancreatitis (Lancet 1994; 343: 1328). The aims of this study were: (1) To evaluate and compare the sensitivity and specificity of serum CDT and $\gamma$-glutamyltransferase (GGT) in detecting high alcohol intake in surgical patients admitted with an acute abdomen: acute pancreatitis (ap) $(n=12)$, other diagnoses (aa) $(n=12)$. (2) To determine the effect of the acute phase response on serum CDT. Patients attending the liver clinic with alcoholic (ald) $(n=12)$ and nonalcoholic (nald) $(n=17)$ chronic liver disease were also evaluated as controls. Sixty one patients gave informed consent to enter the study (33 men, 45-76 years, median 65 ). A standardised questionnaire on drinking habits was completed by the patient and checked with a close relative to confirm alcohol intake. Blood samples were drawn to assay CDT and GGT, and serial daily CDT and $C$ reactive protein (CRP) were taken up to 72 hours. 
The serum CDT was determined using the CDTect kit (Kabi-Pharmacia). Five of 12 ap and six of 12 ald patients drank $>50 \mathrm{~g}$ alco$\mathrm{hol} / \mathrm{day}$ for at least one week. Using cut off points of serum CDT of $20 \mathrm{U} / \mathrm{l}$ (men) and 26 $\mathrm{U} /$ (women), the sensitivity and specificity of CDT in detecting high alcohol intake were as follows:

\begin{tabular}{|c|c|c|c|c|c|}
\hline$(\%)$ & $\begin{array}{l}A l l \\
(G G T)\end{array}$ & $a p$ & $\begin{array}{l}a p+ \\
a a\end{array}$ & ald & $\begin{array}{l}\text { ald }+ \\
\text { nald }\end{array}$ \\
\hline $\begin{array}{l}\text { Sensitivity } \\
\text { Specificity }\end{array}$ & $\begin{array}{l}91(90) \\
94(39)\end{array}$ & $\begin{array}{r}80 \\
100\end{array}$ & $\begin{array}{l}80 \\
93\end{array}$ & $\begin{array}{l}100 \\
100\end{array}$ & $\begin{array}{r}100 \\
94\end{array}$ \\
\hline
\end{tabular}

There was a highly significant correlation between CDT and alcohol intake $(p<0.0001)$ in men. No correlation was found between GGT and alcohol intake. CDT levels fell over the three days of admission but remained as reliable as the admission CDT in detecting alcohol abuse. There was no significant correlation between CDT and CRP (Levene's test of equality, $\mathrm{p}>0.05$ ).

Our results confirm that: (1) CDT is superior to GGT in detecting high alcohol intake. (2) CDT remained reliable in acute abdominal inflammatory disorders, in particular, acute pancreatitis, up to 72 hours from admission. (3) CDT appeared not to be affected by the acute phase response. A larger multicentre study in patients with acute pancreatitis is currently in progress to validate this finding.

\section{Surgery for severe acute pancreatitis}

S SUBRAMANIAN, S K H TOH, C D JOHNSON University Surgical Unit, Southampton General Hospital) The indications and techniques of surgical intervention in complicated pancreatitis are controversial. We present our experience with these patients. All patients with acute pancreatitis referred to one surgeon in 1989-1994 were documented prospectively.

Operation was performed early for signs of peritonitis or progression despite ITU care. Late ( $>10$ days) operations were performed for persisting or new clinical or bacteriological evidence of sepsis, abdominal pain or vomiting. The aim of surgery was to perform a complete debridement and closed drainage. Irrigation was not used. Open packing was used when debridement was incomplete.

All patients had three or more Glasgow criteria on admission or a raised CRP, or both. Two patients died before or during the first operation. Thirty four patients survived one operation: debridement or closed drainage (27), open packing (4), lavage and drainage (2), and internal drainage (1). Of these three (9\%) died later. After primary closure 15 $(50 \%)$ required no further surgery; half required a second $(12,40 \%)$ or multiple (3, $10 \%$ ) laparotomies, eight $(27 \%)$ for further debridement, infection or bleeding, three $(10 \%)$ for pseudocyst, three $(10 \%)$ for closure of pancreatic fistula, and one Beger procedure. Five pancreatic and three enteric fistulas closed spontaneously.

After primary open packing, one patient died and two were converted to closed drainage after 48 hours. One patient was converted to open packing after primary closure complicated by haemorrhage and pancreatic fistula. He ultimately died.

In this mixed secondary and tertiary referral practice, acceptable overall mortality $(14 \%)$ and reoperation rates $(50 \%)$ have been achieved by careful selection of patients and a policy of full debridement.
Gene therapy for pancreatic cancer: nitroreductase transduced cell lines are highly susceptible to the CB 1954 prodrug

N K GREEN, P F SEARLE ${ }^{\star}$, D J YOUNGS, L S YOUNG ${ }^{\star}$, D J KERR ${ }^{\star}$, J P NEOPTOLEMOS (Departments of Surgery and ${ }^{\star}$ Cancer Studies, University of Birmingham) The treatment of advanced pancreatic cancer is limited by the low therapeutic index of active cytotoxic drugs. Virally directed enzyme prodrug therapy permits selective expression of foreign enzymes in tumour cells causing local relatively non-toxic prodrugs. $E$ coli nitroreductase (ntr) converts the prodrug CB 1954 (5-[aziridin-1-yl]-2,4-dinitrobenzamide) to a powerful bifunctional alkylating agent capable of forming interstrand DNA crosslinks. Pancreatic cancer cell lines (SUIT2, BxPC3, and AsPC1) were transcontaining a neomycin resistance gene and the ntr gene under the control of a cytomegalovirus promoter. Neomycin resisproduction of highly cytotoxic agents from duced with the retroviral vector (LNC-ntr)

under physiological conditions are controlled by TIMPs in a sensitive 1: 1 stoichiometric manner. Pancreatic cancer is a highly invasive cancer with a pronounced stromal reaction.

The expression of MMPs, including the newly described MTMMP, a specific MMP2 activator and TIMPs were determined by immunohistochemistry (data not shown), northern analysis, and ISH (Table). TIMP2, an MMP2 specific inhibitor was less often expressed than MMP2 or TIMP1 by the cancers $(\mathrm{p}<0.005)$. MW and @ mRNAs were localised predominantly to cancer epithelial cells but MMP2 was also localised to the tumour stroma in $76 \%$ of cancers $(p<0.02)$

MMP2 expression by stromal and epithelial elements, activation by MTMMP localised to malignant epithelium, and the lower TIMP2 response indicates an aggressive invasive pattern, which may be amenable to novel anti-MMP therapy.

MMP = matrix metalloproteinase; TIMP = tissue inhibitor of $\mathrm{MMP}$; $\mathrm{ISH}=$ in situ hybridisation; $\mathrm{ECM}=$ extracellular matrix; MTMM=membrane type $\mathrm{MW}$

\begin{tabular}{llclc}
\hline $\begin{array}{l}\text { Clone } \\
\text { No }\end{array}$ & Cell line & $I C_{50}(\mu M)$ & $\begin{array}{l}\text { IC } 50 \text { parental } \\
\text { cell line }\end{array}$ & $\begin{array}{l}\text { Sensitivity to } C B \text { 1954 } \\
\text { (v parental) }\end{array}$ \\
\hline S3 & SUIT2 & $3 \cdot 9(3 \cdot 4-4 \cdot 4)$ & $570(549-597)$ & $152(130-174)$ \\
S17 & SUIT2 & $34(29-40)$ & $570(549-597)$ & $17(14-19)$ \\
B3 & BxPC3 & $0 \cdot 7(0 \cdot 6-0 \cdot 8)$ & $350(319-395)$ & $517(474-574)$ \\
B4 & BxPC3 & $1 \cdot 1(0 \cdot 9-1 \cdot 5)$ & $350(319-395)$ & $306(238-376)$ \\
A1 & AsPCI & $1 \cdot 4(1 \cdot 0-1 \cdot 7)$ & $230(203-250)$ & $180(133-217)$ \\
A3 & AsPCI & $3 \cdot 0(2 \cdot 5-3 \cdot 2)$ & $230(203-250)$ & $78(69-87)$ \\
\hline
\end{tabular}

tant clones were assayed for susceptibility to CB 1954 using the Sulforhodamine B protein assay. Ntr protein expression was determined by western blotting and the presence of the $n t r$ gene within the clones was confirmed by PCR. Clones were isolated that demonstrated increased susceptibility to CB 1954 compared with parental cell lines. Values are median (95\% CI); $\mathrm{p}<0.001 ; \mathrm{n}=6$ paired experiments; non-parametric ANOVA.

We are currently screening ntr expressing clones containing the tumour specific promoter CEA, which will allow tumour restricted expression of ntr after in vivo administration. This strategy may lead to a more effective treatment of pancreatic cancer.

MMP and MTMMP upregulation, is not countered by an upregulation of TIMP2 in pancreatic cancer

S R BRAMHALL ${ }^{1}$, N R LEMOINE ${ }^{2}$, G W H STAMP ${ }^{2}$, J P NEOPTOLEMOS ${ }^{1}$ (University Department of Surgery ${ }^{1}$, Birmingham and ICRF ${ }^{2}$ London) MMPs once activated are powerful proteolytic enzymes, which degrade the ECM but

\begin{tabular}{lcc}
\hline & ISH (\%) & Northern (\%) \\
\hline Pancreatic cancer & & \\
MMP1 & - & $0 / 17$ \\
MMP2 & $17 / 17(100)$ & $13 / 14(93)^{\star}$ \\
MMP7 & $5 / 10(50)$ & $15 / 17(88) \dagger$ \\
MMP11 & - & $7 / 17(41) \dagger$ \\
MTMMP & $9 / 14(64)$ & - \\
TIMP1 & $15 / 17(88)$ & $14 / 14(100) \dagger$ \\
TIMP2 & $8 / 11(73)$ & $9 / 17(53) \dagger$ \\
Normal pancreas & & \\
MMP1 & - & $0 / 17$ \\
MMP2 & $1 / 5(20)$ & $0 / 17$ \\
MMP7 & $1 / 2$ & $5 / 17(29)$ \\
MMP11 & - & $0 / 17$ \\
MTMMP & $1 / 4(25)$ & - \\
TIMP1 & $1 / 10(10)$ & $9 / 17(53)$ \\
TIMP2 & $0 / 4$ & $0 / 17$ \\
\hline
\end{tabular}

${ }^{\star} p<0.0001,+p<0.01$ compared with normal pancreas (Fisher's).
Influence of oral fish oil supplementation on nutritional indices in pancreatic cancer patients

S J WIGMORE, J A ROSS, K J TISDALE, C E PLESTER, D C CARTER, $K$ C H FEARON (Department of Surgery, Royal Infirmary, Edinburgh) Pancreatic cancer cachexia is associated with increased energy expenditure and an increased acute phase response. Such cachexia can be modified in animal models by dietary supplementation with fish oil derived fatty acids, however, their effect in human cancer cachexia is unknown. This preliminary mentation on nutritional indices in weight losing pancreatic cancer patients.

Eighteen patients with unresectable pancreatic cancer underwent nutritional assessment (anthropometry, indirect calorimetry, body composition analysis, and serum $\mathrm{C}$ reactive protein (CRP) estimation) before and after supplementation with a median of 12 g/day of fish oil capsules (MaxEPA containing $18 \%$ wlw eicosapentaenoic acid). Ethical permission and informed consent were obtained

All patients were weight losing before fish oil supplementation but after treatment 14 of 18 became weight stable or gained a small amount of weight. Changes in weight were accompanied by a significant reduction in $\mathrm{C}$ reactive protein production at one month.

\begin{tabular}{llll}
\hline & $\begin{array}{l}\text { Before } \\
\text { fish oil }\end{array}$ & $\begin{array}{l}1 \\
\text { Month }\end{array}$ & $\begin{array}{l}3 \\
\text { Months }\end{array}$ \\
\hline Weight change & $-2 \cdot 9$ & $+0 \cdot 3 \dagger$ & $+0 \cdot 3 \dagger$ \\
kg/month & $(2-4 \cdot 6)$ & $(0-0 \cdot 5)$ & $(0-0 \cdot 5)$ \\
Serum CRP & 15 & 10 & 16 \\
mg/l & $(5-24)$ & $(4-18)^{\star}$ & $(10-26)$ \\
REE kCal/kg & 25 & 24 & 25 \\
body weight & $(21-27)$ & $(20-27)$ & $(23-28)$ \\
Total body water & 56 & 55 & 55 \\
as \% body wt & $(49-61)$ & $(51-58)$ & $(50-63)$ \\
\hline
\end{tabular}

Results median (interquartile range). ${ }^{\star} \mathrm{p}<0.002$ Student's two tailed $t$ test. $t p<0.002$ Oldham transformation and regression analysis. study investigates the effect of fish oil supple- 
Overall resting energy expenditure (REE) was unchanged but a significant inverse correlation was observed between reduction in REE and weight gain $(r-0.64, \mathrm{p}<0.04)$

In this preliminary study oral fish oil supplement resulted in arrest of weight loss in patients with pancreatic cancer. The mechanism of this action is unclear but may be via reduction in acute phase protein production. Further controlled studies are required to validate these findings and to identify the precise component of fish oil mediating these effects.

\section{Adjuvant combined radiotherapy and} chemotherapy for pancreatic cancer

$S$ R BRAMHALL for the UK Pancreatic Cancer Trials Group (University Department of Surgery, Queen Elizabeth Hospital, Birmingham) Resection for pancreatic cancer in the West Midlands is associated with a crude two year survival of $16 \%$. The North American GITSG phase HI trial of adjuvant therapy reported a survival improvement with postoperative radiotherapy ( $40 \mathrm{~Gy}$ ) followed by 5 fluorouracil in pancreatic cancer $(43 \%$ two year actuarial survival $v 18 \%$ in controls).

The GITSG protocol was repeated in 35 patients with pancreatic ductal adenocarcinoma and five patients with ampullary adenocarcinoma between 1987 and 1993. The study was censored after six years and 12 months after the last patient was entered There were 26 men and 14 women with a median age of 60 (range 36-76) years. Lymph node (LN) metastases were present in 21 of 40 cases and positive resection margins (PRM) in 14 of 37 . Adjuvant therapy was well tolerated with only one significant related toxicity and no mortality. The median follow up is now $21(8-72)$ months, with a median survival (MST) of $12.9 \quad(95 \% \quad \mathrm{CI}=10.2$ to $25 \cdot 6$ ) months and an overall two year actuarial survival (2YASR) of $36 \%$. In patients with pancreatic ductal adenocarcinoma and PRM the MST was $10(95 \% \mathrm{CI}=8$ to 37$)$ months (2YASR $=36 \%$ ) and in those without
PRM the MST was $13(95 \% \mathrm{CI}=10$ to 33$)$ months $(2 Y A S R=32 \%)(p=N S)$. In patients without LN metastases MST was 28 (95\% $\mathrm{CI}=13$ to 56 ) months (2YASR $=60 \%$ ) and in those with LN metastases MST was $11(95 \%$ $\mathrm{CI}=8$ to 13$)$ months (2YASR $=17 \%)$ $(\mathrm{p}=0.01)$

These data confirm the need for a major randomised trial and suggest that adjuvant therapy may be useful in those patients with $\mathrm{PRM}$, as well as patients without $\mathrm{LN}$ involvement.

The effect of dietary eicosapentaenoic acid supplementation on PBMC cytokine production and the acute phase response in pancreatic cancer

S J WIGMORE, J A ROSS, $\mathrm{K}$ C H FEARON (University Department of Surgery, Royal Infirmary Edinburgh) The acute phase response is raised in patients with pancreatic cancer and has been shown to correlate with increased energy expenditure and decreased survival duration. Cytokines are thought to drive the acute phase response and production of TNF and IL- 6 by peripheral blood mononuclear cells (PBMC) of pancreatic cancer patients is significantly raised compared with controls. Previous work has demonstrated that $n-3$ polyunsaturated fatty acids down regulate proinflammatory cytokine production in healthy volunteers and EPA has been shown to have anticachectic effects (in animal models). This study examines the effect of dietary supplementation with high purity EPA on PBMC cytokine production, $T$ cell function, and acute phase protein production in patients with pancreatic cancer.

Six patients with unresectable pancreatic cancer received a total of $92 \mathrm{~g}$ of $95 \%$ pure EPA (Scotia UK) in the form of gelatin coated capsules over one month. Peripheral blood mononuclear cells were isolated from these patients before and after supplement and from six healthy volunteers. Spontaneous and LPS induced TNF and
IL-6 release was measured by ELISA. PBMC supernatants were added to isolated human hepatocytes and acute phase protein production was measured by ELISA. Uptake of $3 \mathrm{H}$ thymidine was used to assess $\mathrm{T}$ cell blastogenesis in response to phytohaemagglutinin.

EPA supplement resulted in reduction of TNF and IL- 6 production, increased T cell blastogenesis in response to PHA. Production of CRP in response to PBMC supernatants by isolated human hepatocytes was reduced.

\begin{tabular}{lcc}
\hline & 0 & $L P S$ \\
\hline Controls $(5 \mu g / m l)$ & & \\
IL-6 autologous serum & 1098 & 7511 \\
Fetal calf serum & 937 & 3229 \\
TNF autologous serum & 139 & 842 \\
Fetal calf serum & 126 & 645 \\
CRP (ng/ml) & $40 \cdot 7$ & $55 \cdot 3$ \\
PHA & 0 & 100 \\
PHA conc counts & 551 & 8781 \\
Before supplement $(5 \mu g / m l)$ & & \\
IL-6 autologous serum & 4534 & 11255 \\
Fetal calf serum & 3168 & 10169 \\
TNF autologous serum & 218 & 1909 \\
Fetal calf serum & 487 & 1310 \\
CRP (ng/ml) & 107 & 196 \\
PHA & 0 & 100 \\
PHA conc counts & 504 & 3478 \\
After supplement( $\mu g / m l)$ & & \\
IL-6 autologous serum & 1733 & 7300 \\
Fetal calf serum & $715^{\star}$ & $3570^{\star}$ \\
TNF autologous serum & 54 & 799 \\
Fetal calf serum & 199 & $643^{\star}$ \\
CRP (ng/ml) & 89 & 96 \\
PHA & 0 & 100 \\
PHA conc counts & 1067 & $9886^{\star}$ \\
&
\end{tabular}

${ }^{\star} \mathrm{p}<0.05$ ANOVA.

These data support our clinical findings that the anticachectic effect of EPA in pancreatic malignancy may be mediated through suppression of cytokine production and the hepatic acute phase response. Values for cytokines and $T$ cell blastogenesis were no different from controls after treatment, however, the acute phase protein stimulating potential of supernatants was still higher than that observed in control supernatants. 